\title{
Preparation of Amorphous Poly(aryl ether nitrile ketone) and Its Composites with Nano Hydroxyapatite for 3D Artificial Bone Printing
}

Xinshuai Gao, ${ }^{\dagger}+\grave{+}$ Honghua Wang, ${ }^{*}$, Xu Zhang, ${ }^{\dagger}$ Xinming Gu, $"$ Yuzhe Liu, ${ }^{\perp}$ Guangyuan Zhou, * Shifang Luan, *,

†State Key Laboratory of Polymer Physics and Chemistry, Changchun Institute of Applied Chemistry, Chinese Academy of Sciences, Changchun 130022, China

*University of Science and Technology of China, Hefei 230026, China

§Division of Energy Materials (DNL22), Dalian Institute of Chemical Physics of the Chinese Academy of Sciences, Dalian 116023, China

"Department of Oral Implantology, School and Hospital of Stomatology, Jilin University, Changchun 130021, China

${ }^{\perp}$ Department of Orthopaedics of the Second Hospital, Jilin University, Changchun 130022, China 


\title{
Corresponding Authors
}

\author{
*E-mail: wanghh22@dicp.ac.cn (H.W.) \\ *E-mail: gyzhou@dicp.ac.cn (G.Z.). \\ *E-mail: sfluan@ciac.ac.cn (S.L.).
}

\section{EXPERIMENTAL SECTION}

Materials for Synthesis of PEK-CN. Phenolphthalein (PHT, 99\%), toluene (99\%) and potassium carbonate $\left(\mathrm{K}_{2} \mathrm{CO}_{3}, 99 \%\right)$ were purchased from Beijing Chemical Plant, Beijing, China. 4,4'-Difluorobenzophenone (DFBP, 99\%) was sourced from Changzhou Huashan Chemical Co. Ltd, Changzhou, China. 2,6-Dichlorobenzonitrile (DCBN, 99\%) was purchased from Alfa Aesar (China) Chemical Co. Ltd, Shanghai, China. Nano hydroxyapatite (nHA, 97\%, 100nm) and 4-fluorobenzophenone (FBP, 99\%) were purchased from Aladdin Industrial Corporation, Shanghai, China. All the above materials were used as received. Tetramethylene sulfone (TMS, 98\%) was purchased from Tianjin Guangfu Co. Ltd, Tianjin, China, and used after purification through reduced pressure distillation.

Synthesis of PEK-CN. PEK-CN was synthesized via nucleophilic substitution poly-condensation reaction of PHT, DCBN, and DFBP in TMS, with $\mathrm{K}_{2} \mathrm{CO}_{3}$ as the catalyst. For example, PHT (100mmol, 31.83g), DCBN (70mmol, 12.04g), DFBP (30mmol, 6.55g), FBP (3mmol, 0.60g), toluene $(50 \mathrm{ml})$, TMS $(90 \mathrm{ml})$ and $\mathrm{K}_{2} \mathrm{CO}_{3}(115 \mathrm{mmol}, 15.89 \mathrm{~g})$ were 
placed in a three-necked flask equipped with a mechanical stirrer, a nitrogen inlet, and a Dean-Stark trap fitted with a condenser. The reaction mixture was heated to $150^{\circ} \mathrm{C}$ and kept refluxing for $2.5 \mathrm{~h}$ under stirring, then water and toluene were removed over time. Afterwards, the temperature was raised to $200^{\circ} \mathrm{C}$ and the mixture was kept reacting for another $2.5 \mathrm{~h}$. Then it was poured into the mixed solution of ethanol and deionized water, stirred by a glass rod at the same time. Next, the resulting product was crushed to powders, purified by boiling, washed six times and dried at $150^{\circ} \mathrm{C}$ under vacuum for $24 \mathrm{~h}$.

Characterizations of PEK-CN. ${ }^{1} \mathrm{H}$ spectra were obtained on a Varian Unity $600 \mathrm{MHz}$ instrument by using tetramethylsilane as the internal reference and $C D C l_{3}$ as the solvent (Figure S1). The chemical shifts were assigned to the hydrogen atoms on the molecular structure clearly. $\delta: 7.96\left(H_{6}\right), 7.79\left(H_{10}\right), 7.75\left(H_{4}\right), 7.59\left(H_{8}\right), 7.40-7.34\left(H_{2}, H_{3}\right), 7.30\left(H_{5}\right)$, $7.09\left(H_{1}\right), 7.03\left(H_{9}\right), 6.54\left(H_{7}\right)$.

IR spectra were recorded on FT-IR Fourier transform infrared spectrometer, in the range of $4000-400 \mathrm{~cm}^{-1}$ (Figure $\left.\mathrm{S} 2\right) . \quad v(=\mathrm{C}-\mathrm{H}, \quad$ benzene $) \quad\left(3066 \mathrm{~cm}^{-1}\right), \quad v(\mathrm{C} \equiv \mathrm{N}) \quad\left(2231 \mathrm{~cm}^{-1}\right), \quad v(\mathrm{C}=\mathrm{C}$, benzene) $\left(1594 \mathrm{~cm}^{-1}, 1500 \mathrm{~cm}^{-1}\right.$ and $\left.1462 \mathrm{~cm}^{-1}\right), v(\mathrm{C}=\mathrm{O}$, lactone ring five membered $)(1775$ $\left.\mathrm{cm}^{-1}\right), v(\mathrm{C}-\mathrm{CO}-\mathrm{C})\left(1244 \mathrm{~cm}^{-1}\right), v_{a s}(\mathrm{C}-\mathrm{O}-\mathrm{C})\left(1163 \mathrm{~cm}^{-1}, 1021 \mathrm{~cm}^{-1}\right), v(\mathrm{C}-\mathrm{O}-\mathrm{C})\left(930 \mathrm{~cm}^{-1}\right)$.

Thermal Properties Tests. Thermo Gravimetric Analyzer (TGA) measurements were performed on a Mettler Toledo TGA analyzer at a heating rate of $10 \mathrm{~K} \mathrm{~min}{ }^{-1}$ in nitrogen. Differential Scanning Calorimeter (DSC) measurements were performed on a Mettler Toledo DSC 1 instrument at the same heating rate of $10 \mathrm{~K} \mathrm{~min}^{-1}$ in nitrogen. 
Rheological Measurements. Shear rheology tests were carried out on a Discovery Hybrid Rheometer (TA Instruments) under air, variable temperature rheology from $320^{\circ} \mathrm{C}$ to $400^{\circ} \mathrm{C}$ and constant temperature rheology at $360^{\circ} \mathrm{C}$ and $380^{\circ} \mathrm{C}$ were tested respectively.

Filaments Preparation for 3D Printing. To ensure the moisture content of the resin pellets $<0.02 \mathrm{wt} \%$, pellets of PEK-CN should be dried at $150^{\circ} \mathrm{C}$ under vacuum for $24 \mathrm{~h}$ avoiding lots of bubbles during 3D printing process. Then the pellets were made into filaments of 1.75 $\pm 0.05 \mathrm{~mm}$ diameter at rotating of $100 \pm 10 \mathrm{r} / \mathrm{min}$ and temperature of $330 \pm 10^{\circ} \mathrm{C}$ on filaments produced system, including filaments extruded equipment and filaments traction equipment.

3D Printing Process. The models of 3D printing were designed and built in the Ultimaker Cura 3.4.1 firstly and saved in STL format, then translated into gcode format. The 3D printer named Doctor 200 (R\&D by Xian Jiaotong University, Xian, China) was fed with the filaments of PEK-CN to fabricate the samples via FDM method.

Morphological Observation. The sectional morphology of 3D printed samples was characterized by scanning electron microscopy (SEM). 3D printed samples were cryofractured after immersion in liquid $N_{2}$ for 10 min, sputter coated with $200 \AA$ of gold, and viewed using the Hitachi XE-100 + EDAX SEM.

Porosity Measurements. Images of 3D printed samples were obtained by SkyScan1172 Desktop micro-computed tomography (micro-CT) with a cone beam source operating at 100 $\mathrm{kV}$ (voltage) and $90 \mu \mathrm{A}$ (current). The first step was the acquisition of images in various angular projections of the samples along a rotation of $180^{\circ}$, with $0.2^{\circ}$ rotational steps. The 
second stage consisted of the reconstruction of images of cross-sections from the images of the angled projections through the Feldkamp cone-beam volumetric reconstruction algorithm. All images had a resolution of $4.8 \mu \mathrm{m}$ in our work. After obtaining the reconstructed images from micro-CT, slices were processed for further analysis.

Mechanical Properties Tests. The tensile test was measured with dumbbell-shaped specimens with size of $110 \mathrm{~mm}$ (length) $\times(10 \pm 0.5) \mathrm{mm}$ (width) $\times 4 \mathrm{~mm}$ (thickness) according to $\mathrm{GB} / \mathrm{T} 1040.2-2006 \mathrm{BA}$, and the tensile rate was $2 \mathrm{~mm} / \mathrm{min}$. The bending test was measured with rectangle-shaped specimens with size of $80 \mathrm{~mm}$ (length) $\times(10 \pm 0.5) \mathrm{mm}$ (width) $\times(4 \pm$ 0.2) $\mathrm{mm}$ (thickness) according to GB/T 1449-2005, and the deformation rate was $2 \mathrm{~mm} / \mathrm{min}$. The compressive test was measured with rectangle-shaped specimens with size of $10 \mathrm{~mm} \times 10 \mathrm{~mm} \times(4 \pm 0.1) \mathrm{mm}$ according to $\mathrm{GB} / \mathrm{T} 1041-2008$, and the deformation rate was $2 \mathrm{~mm} / \mathrm{min}$. All above mechanical properties were measured at room temperature $\left(25^{\circ} \mathrm{C}\right)$ by an electronic universal testing machine from MTS Industrial Systems (China) Co., Ltd. The izod unnotched impact test was measured with rectangle-shaped specimens with size of $(80 \pm$ 2) $\mathrm{mm}$ (length) $\times(10 \pm 0.2) \mathrm{mm}($ width $) \times(4 \pm 0.2) \mathrm{mm}$ (thickness) according to GB/T $1843-2008$, and the impact rate was $3.5 \mathrm{~m} / \mathrm{s}$. Five repeated specimens were tested and the final result was the average value of five specimens.

In Vitro Cytotoxicity Assay. The cytotoxicity test was evaluated with live/dead assay (BestBio, China) using L929 cells (iCell Bioscience, China) and cell counting kit-8 (CCK-8, Dojindo, Japan) assay using MC3T3-E1 cells (FuHeng BioLogy, China). Cells were cultured in high glucose DMEM media (Hyclone, USA) supplemented with $10 \%$ fetal bovine serum 
(Hyclone, USA) and 1\% penicillin-stretomycin (Coolaber, China) in a humidified atmosphere of $5 \% \mathrm{CO}_{2}$ at $37^{\circ} \mathrm{C}$. Prior to live/dead assay, cells were seeded on the sterile samples placed in a $24-w e l l$ plate at a density of $5 \times 10^{4}$ cells/well and incubated at $37^{\circ} \mathrm{C}$ for $24 \mathrm{~h}$. Then adhering cells were stained for $15 \mathrm{~min}$ in a solution of Calcein AM and 5min in PI. After that, a fluorescence microscope (Nikon, Japan) was used for imaging the samples. CCK-8 assay was carried out according to GB/T 16886.5-2003 and GB/T 16886.12-2003. Extracts were derived from incubating the sterile samples of PEK-CN in high glucose at $37^{\circ} \mathrm{C}$ for $72 \mathrm{~h}$. Cell culture medium was used as a negative control. Cells were seeded in 96-well plates at a density of $1.5 \times 10^{4}$ cells per well. After $24 \mathrm{~h}$, the culture mediums were substituted by the extracts and incubated for $24 \mathrm{~h}$. Then, $10 \mu \mathrm{lCCK}-8$ was added to each well and incubated for $1 \mathrm{~h}$, finally we measured the absorbance values at $450 \mathrm{~nm}$ using a microplate reader (Biotek, USA).

Composites with nHA. PEK-CN/nHA composites with different nHA contents were obtained by adjusting the mass fraction of PEK-CN and nHA. Firstly, PEK-CN powders and nHA were mixed simply in proportion in the pulverizer, then the composite powders were molten and extruded in the mini twin-screw extruder under the rotating of $60 \mathrm{r} / \mathrm{min}$ at $370^{\circ} \mathrm{C}$. Relying on the shear force from twin-screw to the composite, nHA could be evenly dispersed in the polymer resin. Finally, five composite pellets were prepared respectively. 
Scheme S1. Process of Micro-CT Testing by X-ray Scanning and 3D Visualization of Solid and Pore

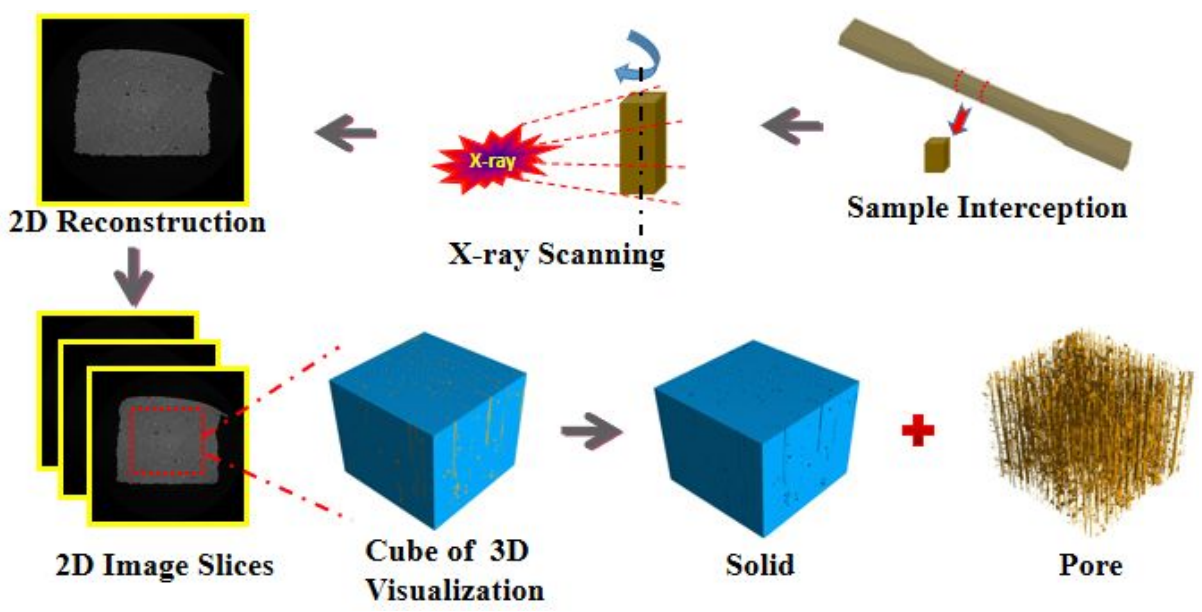

Scheme S2. Process from the Powders of PEK-CN/nHA Composites to the 3D Printed Samples

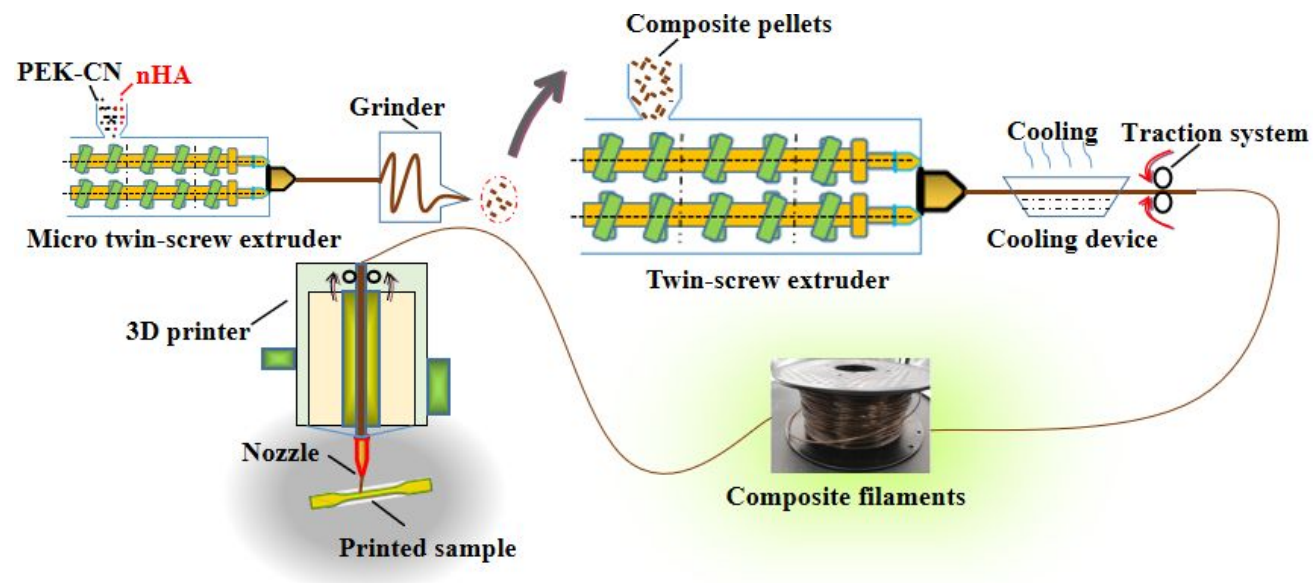



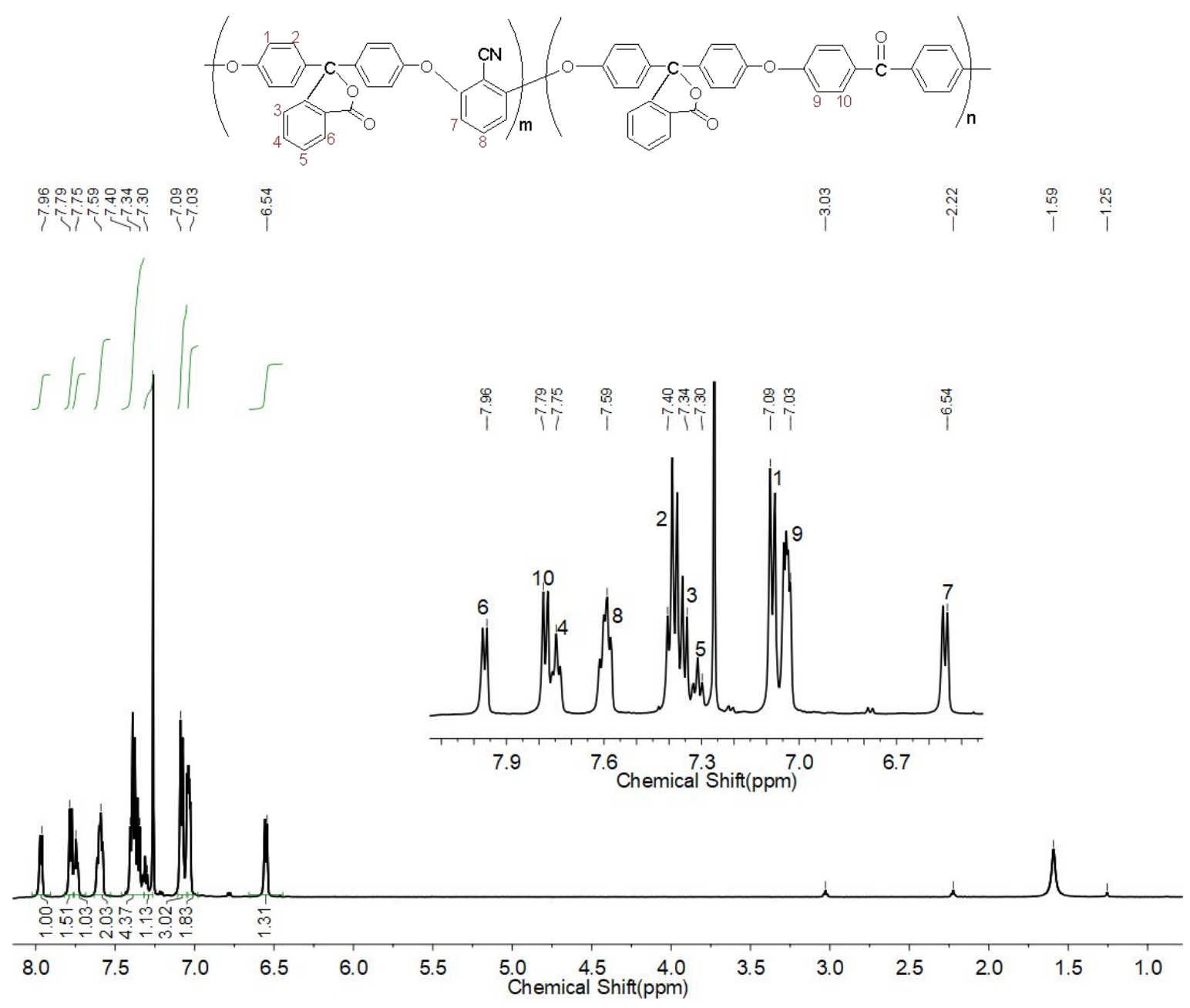

Figure S1. ${ }^{1} \mathrm{H}$ NMR spectra of PEK-CN $\left(600 \mathrm{MHz}, C D C l_{3}\right): \delta 7.96\left(H_{6}, \mathrm{~d}, 1 \mathrm{H}\right), 7.79\left(H_{10}, \mathrm{~d}\right.$, 2H), 7.75( $\left.H_{4}, \mathrm{t}, 1 \mathrm{H}\right), 7.59\left(H_{8}, \mathrm{~m}, 2 \mathrm{H}\right), 7.40-7.34\left(H_{2}, H_{3}, \mathrm{~m}, 4 \mathrm{H}\right), 7.30\left(H_{5}, \mathrm{t}, 1 \mathrm{H}\right), 7.09\left(H_{1}, \mathrm{~d}\right.$, $3 \mathrm{H}), 7.03\left(H_{9}, \mathrm{~m}, 2 \mathrm{H}\right), 6.54\left(H_{7}, \mathrm{~d}, 2 \mathrm{H}\right)$. 


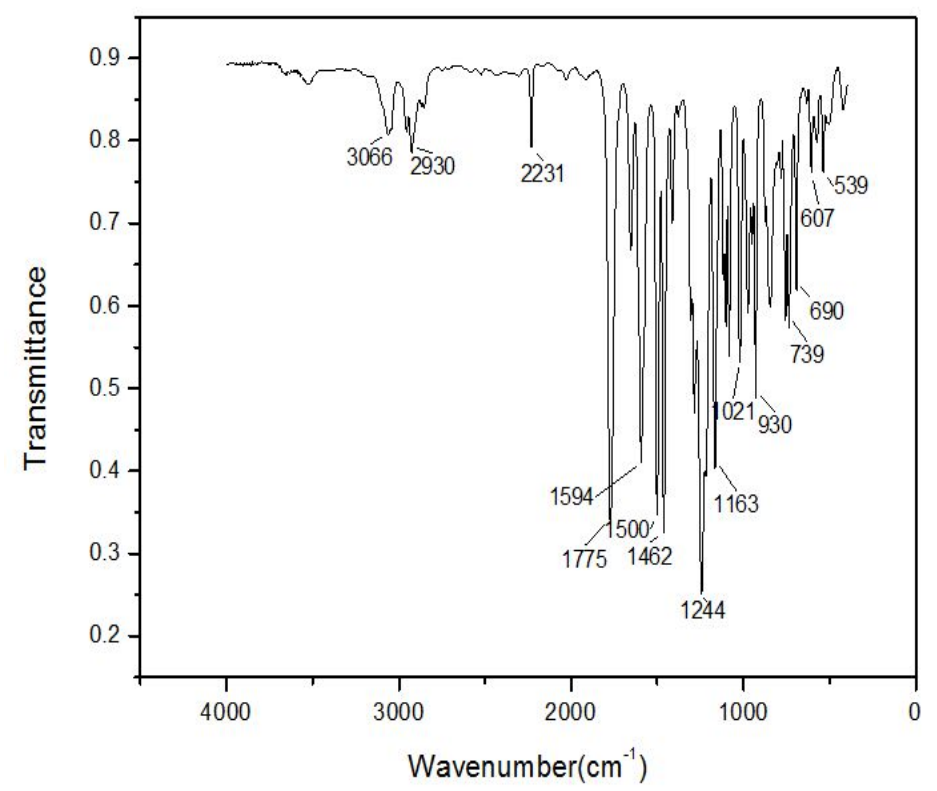

Figure S2. IR spectra of PEK-CN in the range of $4000-400 \mathrm{~cm}^{-1}$ 


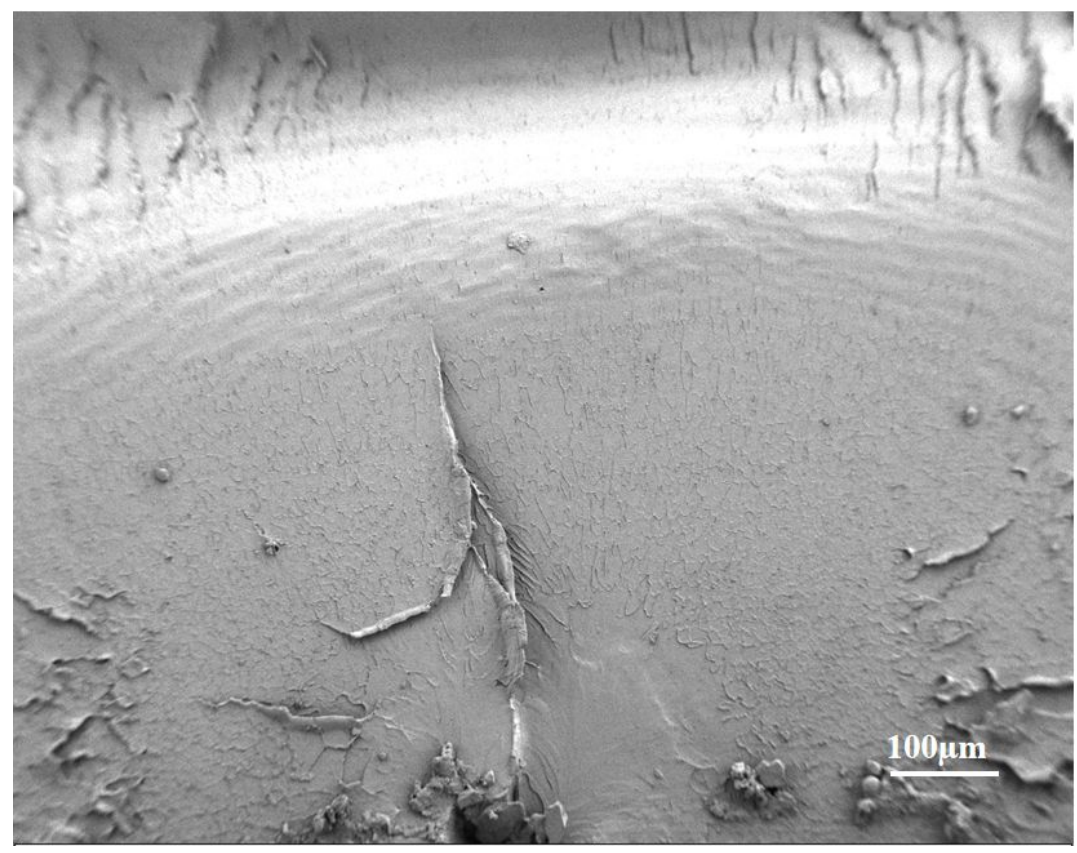

Figure S3. SEM image of injection-moulded PEK-CN sample 


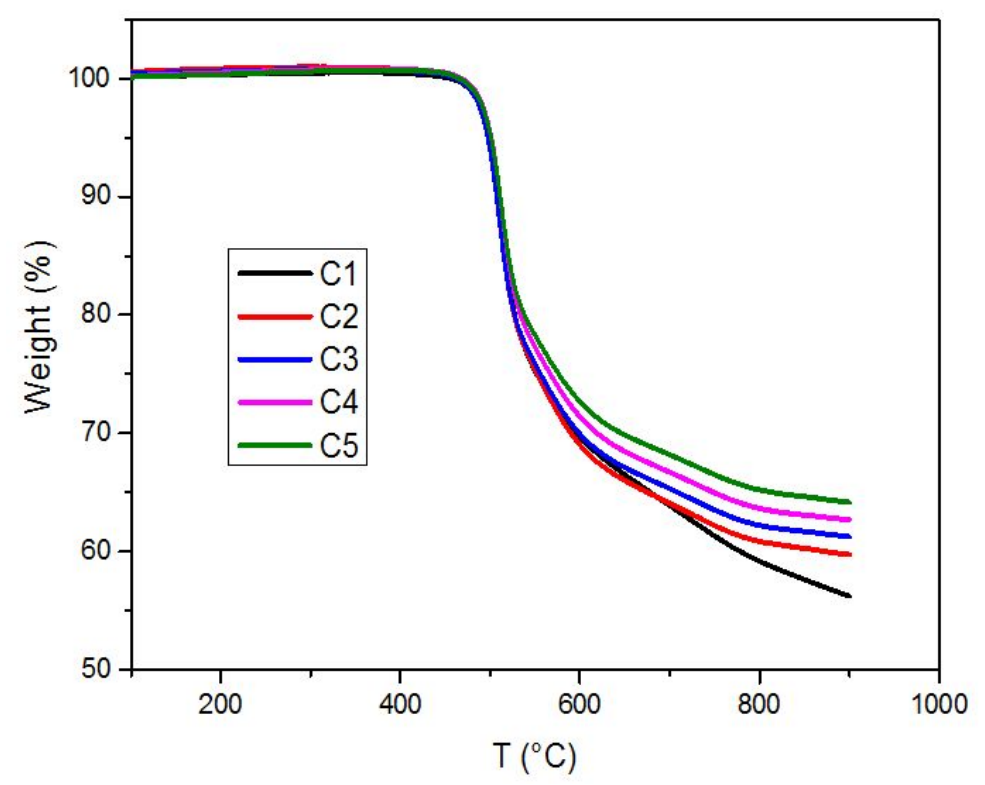

Figure S4. Curves of TGA testing at a heating rate of $10 \mathrm{~K} \mathrm{~min}^{-1}$ in nitrogen

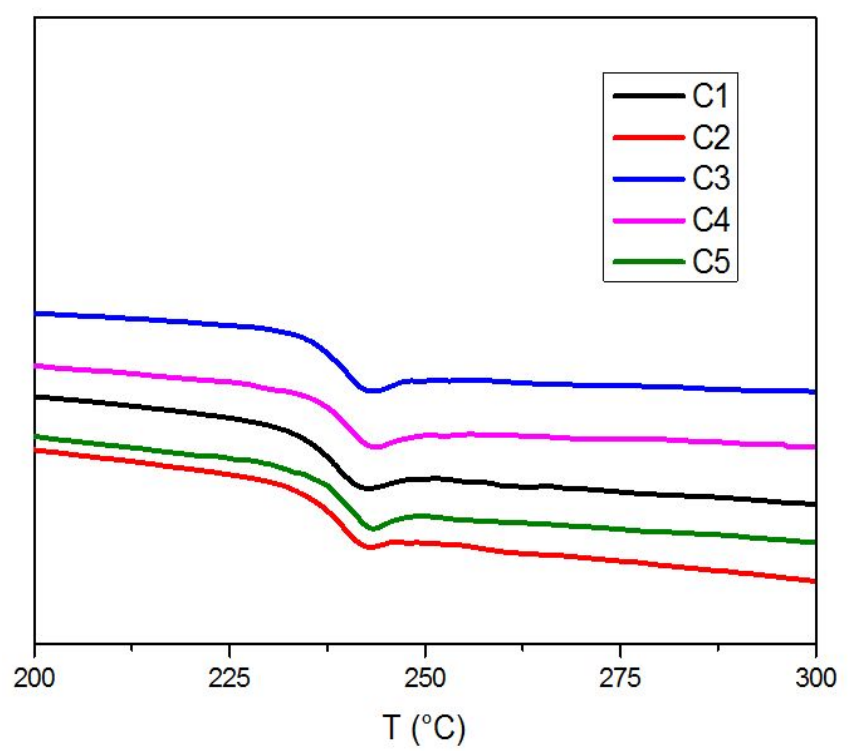


Figure S5. Curves of DSC testing at a heating rate of $10 \mathrm{~K} \mathrm{~min} \mathrm{~min}^{-1}$ in nitrogen

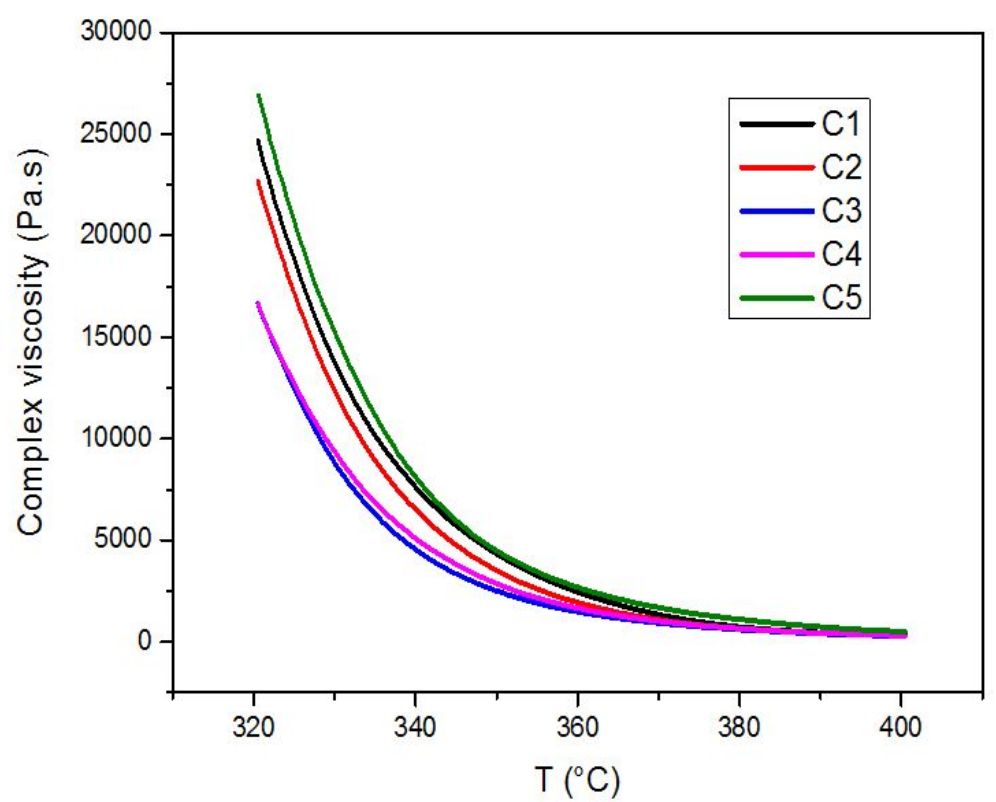

Figure S6. Variable temperature rheological behaviors from $320^{\circ} \mathrm{C}$ to $400^{\circ} \mathrm{C}$ 


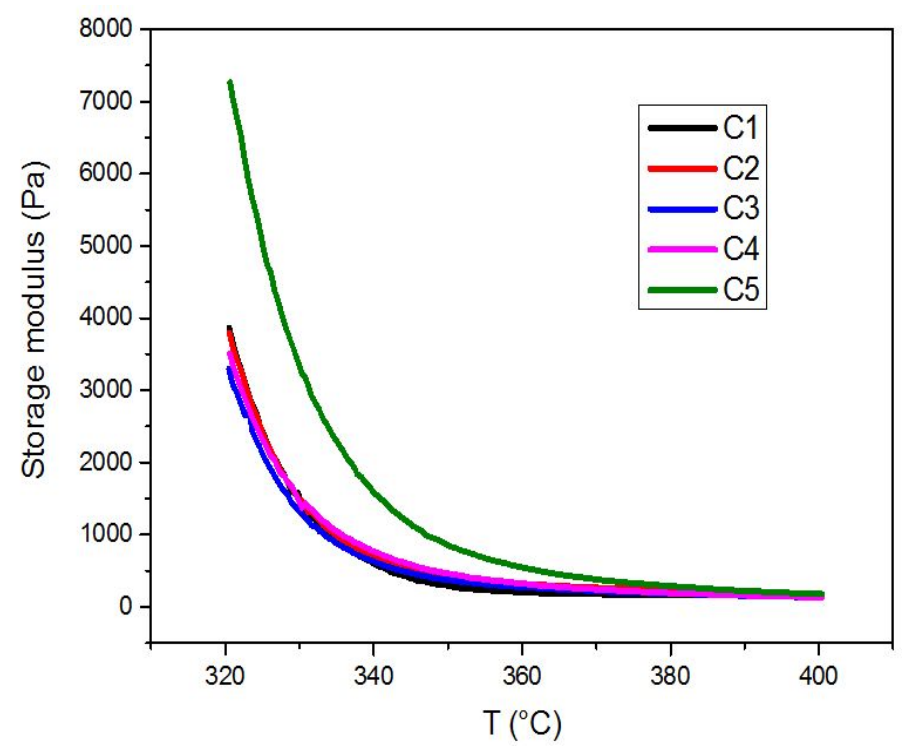

Figure S7. Changes of storage modulus from $320^{\circ} \mathrm{C}$ to $400^{\circ} \mathrm{C}$
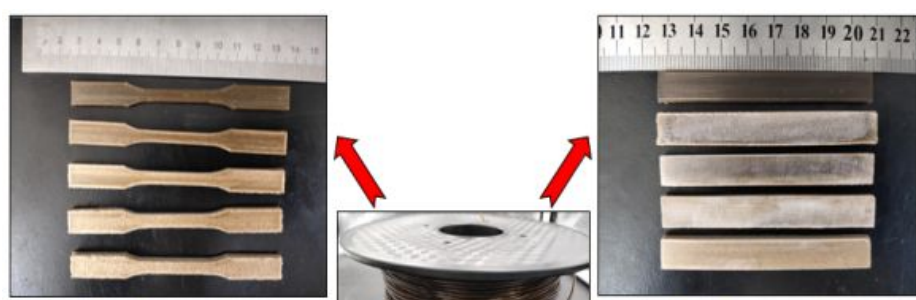

Tensile samples

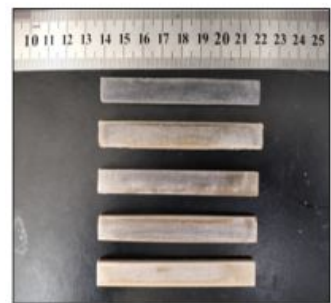

Bending samples

Impact samples

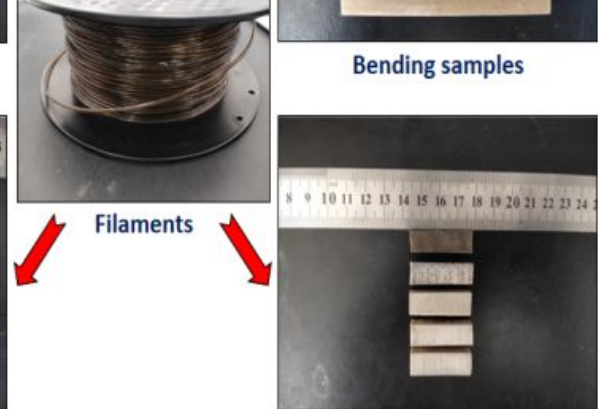

Compressive samples

Figure S8. Samples of five 3D printed composites for mechanical properties testing 


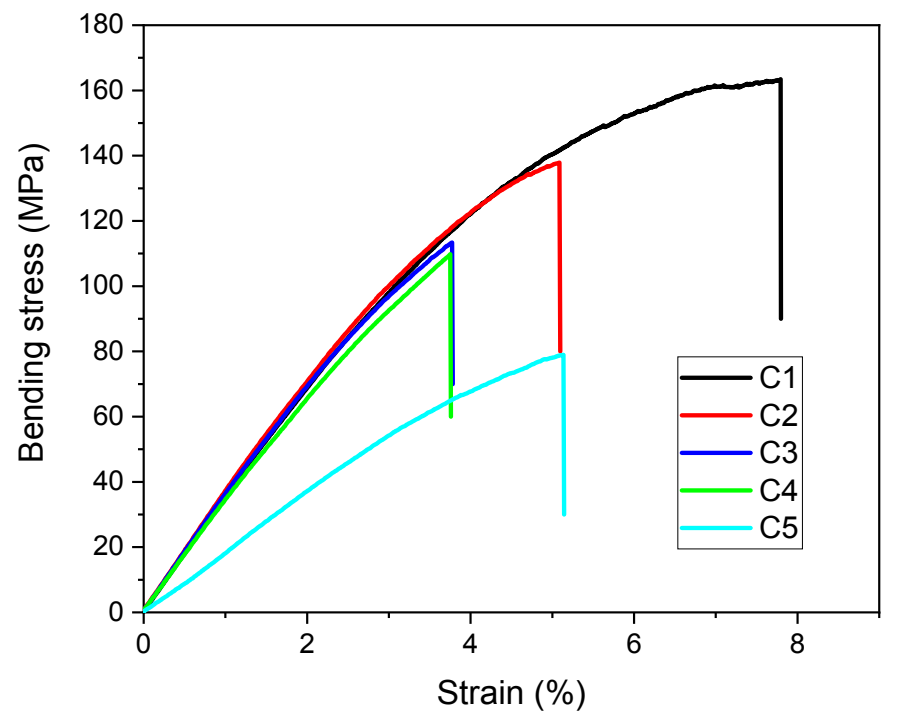

Figure S9. Bending properties of five 3D printed composites testing at the rate of $2 \mathrm{~mm} / \mathrm{min}$ 


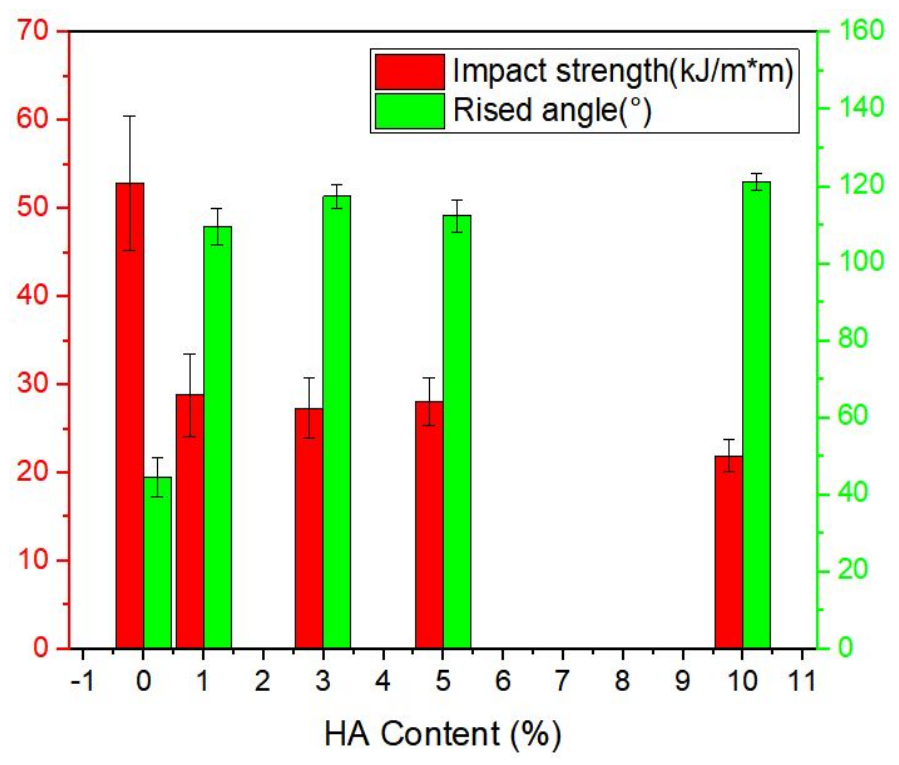

Figure S10. Impact properties of five 3D printed composites testing at the rate of $3.5 \mathrm{~m} / \mathrm{s}$

Table S1. Parameters of 3D Printing

$\begin{array}{cccccc} & \text { nozzle temp } & \text { heat platform temp } & \text { nozzle moving speed } & \text { layer thickness } & \text { nozzle diameter } \\ \text { items } & {\left[{ }^{\circ} \mathrm{C}\right]} & {\left[{ }^{\circ} \mathrm{C}\right]} & {[\mathrm{mm} / \mathrm{s}]} & {[\mathrm{mm}]} & {[\mathrm{mm}]} \\ \text { parameters } & 380 & 260 & 40 & 0.2 & 0.2\end{array}$


